See discussions, stats, and author profiles for this publication at: https://www.researchgate.net/publication/263616540

\title{
Examining emerging ICT's adoption in SMEs from a dynamic process approach
}

Article in Information Technology \& People · February 2014

DOI: 10.1108/TP-03-2013-0044

\section{CITATIONS}

34

3 authors, including:

\section{Sunday C. Eze}

Landmark University

31 PUBLICATIONS 150 CITATIONS

SEE PROFILE
982

Yanqing Duan

University of Bedfordshire

129 PUBLICATIONS 1,403 CITATIONS

SEE PROFILE

Some of the authors of this publication are also working on these related projects:

Project Sustainable SCM View project

Project Article View project 


\section{Examining emerging ICT's adoption in SMEs from a dynamic}

ICT's adoption in SMEs

\author{
process approach \\ Sunday Chinedu Eze, Yanqing Duan and Hsin Chen \\ Business Systems, University of Bedfordshire, Luton, UK
}

\begin{abstract}
Purpose - This paper aims to advance information and communication technologies (ICT) adoption research and practice by examining and understanding the emerging ICT adoption in small and medium enterprises (SMEs) from a dynamic process perspective using actor-network theory (ANT). Design/methodology/approach - This study employs a qualitative approach to investigate how services SMEs are constantly engaging in ICT adoption for improving business performance. Two rounds of interviews were conducted with 26 interviewees. Data collected from the unstructured and semi-structured interviews were analysed to understand the dynamic adoption process, actors involved and their interactions.

Findings - The findings reveal the recursive and dynamic nature of the emerging ICT adoption process and the constant interactions and negotiations of various actors. Underpinned by the key concepts of ANT and validated by the empirical data, a framework is developed to depict the stages of dynamic process of emerging ICT adoption, the actors involved and the associated key activities.

Research limitations/implications - Qualitative research is interpretive in nature and the size of the sample used is limited. These limitations require caution for the generalization of the findings. The framework can be further validated across a wider population using mixed methods combining qualitative and quantitative approaches.

Practical implications - Emerging ICT adoption has moved from a simple adopters' participation process to involving various actors that constantly interact and influence the process. SMEs manager can be influenced by and influence the technology advancement. As a result, SMEs need constantly interact with various human and non-human actors to keep up with the new ICT development and benefit from the emerging opportunities.

Originality/value - The research focuses on the emerging ICT adoption in SMEs from the dynamic process perspective using ANT. It advances ICT adoption research and practice by developing a framework to depict the dynamic and interactive nature of ICT adoption process, and the actors involved and their interactions in the adoption process.
\end{abstract}

Keywords Adoption, Technology adoption, Actor-network theory,

Small- and medium-sized enterprises (SMEs)

Paper type Research paper

\section{Introduction}

The sustained success of any small and medium enterprises (SMEs) is not only enabled by the use of information and communication technologies (ICT), but also dependent on the company's ability to constantly adopt and make the best use of emerging ICT for innovation and business competitiveness. Emerging ICT in this context is a broad term to include any new ICT development or improved ICT applications. Examples include web and enterprise 2.0, cloud computing, social network systems, open source applications, and smart phones and digital and mobile devices. Findings from literature reveal that although significant efforts have been made to study ICT adoption and diffusion, the diversity of the research in terms of theory and methodology is very low. Although most studies have used traditional adoption theories (e.g. technology acceptance model (TAM) and diffusion of innovation (DOI)),

\section{3}

Received 6 March 2013 Revised 7 May 2013 Accepted 2 August 2013

\footnotetext{
Information Technology \& People Vol. 27 No. 1, 2014 pp. $63-82$

(C) Emerald Group Publishing Limited 0959-3845 DOI 10.1108/ITP-03-2013-0044
} 
ITP

27,1

64

these theories have been criticised as being static in nature (Al-Natour and Benbasat, 2009) and are unable to capture the constant development of ICT and their adoption and post-adoption development. Most of these theories focus more on the technical aspects with less emphasis being placed on the role of human agency (Barrett et al., 2006). To bridge the deterministic conception held by the pioneers of these theories, it has been argued that more research attempts are needed to understand the dynamic nature of emerging ICT adoption, roles and interactions among actors in shaping adoption and post-adoption over time.

Prior ICT adoption studies mainly used deductive approaches involving theory confirmation and hypotheses testing. Although this research design has certain advantages, it does have limitations. It regards ICTs adoption as a one-off action and focuses on factors affecting the decision making at one particular decision point. It has ignored the fact that ICT adoption can be an ongoing process involving a variety of stakeholders and their interactions. Theories and models should treat ICT adoption as a dynamic, interactive and evolving process, instead of a static and one-off action.

The majority of ICT adoption research is based on the quantitative methods due to the dominant use of deductive approach for hypothesis testing. For example, Williams et al. (2009) revealed that the majority of studies (about 65 per cent) employed a quantitative approach. Other methods, such as interviews, mathematical modelling, field study, secondary data analysis, action research, were rarely used in ICT adoption research.

Therefore, this study aims to advance ICT adoption research by examining the adoption from a dynamic process perspective. The study attempts to develop better understanding and new insights into how SMEs are continuingly interact with various actors and adopting and adapting emerging ICTs which are constantly innovating and evolving. Based on an extensive literature review, actor-network theory (ANT) is employed as a theoretical lens to inform our investigation. Being aware of the current criticism and limitations on the dominant use of the quantitative approach in adoption research, this study uses a qualitative approach. Unstructured and semi-structured interviews were used and deductive and inductive approaches were followed in data analysis. Two rounds of interviews involving 26 interviewees were conducted. A conceptual framework underpinned by the ANT concepts is developed to depict the dynamic process; the actors involved and associated activities. The paper first reviews ANT as a theoretical underpinning to understand the dynamic and interactive nature of emerging ICT adoption. It then discusses the stages of data collection methods and data analysis procedures. It finally presents the framework and discusses the future research. The paper raises awareness on the necessity of examining ICT adoption and post-adoption development from a dynamic process perspective and urges researchers in this area to diversify adoption research by employing alternative theories and qualitative approaches.

\section{Theoretical underpinning}

With the rapid development and deployment of emerging ICTs, there has been an upsurge of interest in studying ICT adoption and diffusion. As a result, a substantial amount of papers have been published in this area. TAM and its extended models, DOI and deductive approaches using survey-based methods have dominated the ICT adoption studies for decades. It is argued by the authors that as ICT is constantly evolving and innovating, the adoption of the emerging ICT is also a continuing, iterative and dynamic process. Future adoption research should focus their attention to 
understand ICT adoption from a dynamic process perspective. Traditional adoption theories (e.g. TAM and DOI) developed by previous researchers have contributed to technology adoption studies in the past, but they have limitations in capturing constant technology advancements and the dynamic and interactive nature of technology adoption and diffusion. Also, theories, such as the social shaping of technology and social construction of technology, do not pay sufficient attention to the dynamic and interactive nature of technology adoption and diffusion. They only examined one aspect of interplay (the social) and ignored the roles played by the technology. Theories that explore the implications of the interactions between the social and technical integration are needed given that what makes information system (IS) unique is the social-tech integration (Bostrom et al., 2009, Hanseth et al., 2004). Studies (Bagozzi, 2007, Venkatesh et al., 2007, Orlikowski and Lacono, 2001) have been calling on a new theoretical perspective that will boost our understanding of the technology (Lee and Oh, 2006), as well as, how the technology can be implemented taking into accounts of their broader context (Silva, 2007, Schwarz and Chin, 2007). These have motivated the proliferation and application of ANT (Silva, 2007) in the area of IT adoption and implementation.

The strength of ANT in understanding ICT adoption lies on its emphasis on studying both the human and non-human entities (Latour, 2005). ANT maintains a distinctive view of society and sees it as a network of human and non-human actors. ANT attempts to address the role technology plays in a social setting and the process by which the technology bilaterally influences the social setting over time (Marres, 2004). The theory rejects both the philosophy of technology and social determinism (Latour, 1987, Callon, 1986) for downplaying the ongoing and dynamic interaction between social and technological factors. ANT recognises that human and non-human actors are not independent; instead, it is the ongoing actions of human with the non-human that help in assessing the advantages of any technology before its development and adoption. An actor which may be human or non-human is defined "as any element which bends, shape around itself, make others elements depend upon itself and translates their wills into the language of its own" (Callon and Latour, 1981, p. 286). ANT has been recognised as having immense potential in understanding complex social interactions associated with technology implementation. Hanseth et al. (2004) argue that ANT can offer us a rather rich set of concpets to understand the relationship betwwen the technological artifact and the technology-in-practice. According to Faraj et al. (2004) when people (human actors) come into a network; they come with their ideas, motives and intensions which they try to impose on the technology (non-human actor) they intend to develop and/or adopt. When the key actor - a competing actor that ensures that other accept its claims in technology adoption and development interests are not in line with other actors beliefs (Sarker et al., 2006), the opportunity, for successful development and/or adoption becomes limited and thus results to movement (back and forth) of actor (Sarker et al., 2006). The network tends to be stronger where the interest of all human actors are aligned in the technology, and all actors have accepted the decisions of the key actor. On the contrary, the network becomes weaker where other actors challenge the decisions of others either because new ICT has evolved or the previous applications in use cannot meet the organisations current needs thereby causing closure by redefinition of a problem (Bijker et al., 1989). Any actor that cannot meet the key actor's decision leaves the network, while others join the network. ANT recognises the unsteady and mutual influence of social and technical (Sarker et al., 2006) and represents an iterative process that depicts how
ICT's adoption in SMEs

65 
ITP

27,1

66 actors conform or reject the original design which may subsequently results to new design and adoption interest (Faraj et al., 2004, p. 189). This is the position of ANT since it does not take for granted neither the existence of technology nor the social world instead ANT tries to recognise the attributes of non-human actors as both can modify a state of affair (Andrade and Urquhart, 2010, p. 355)

ANT has gained considerable attention in the IS field and many IS scholars have applied it in their work (Elbanna, 2007). Hanseth et al. (2004) point pout that ANT may contribute to the IS field not only by means of its concpetual vocabulary, but also by insiraing various ANT case studies providing rich understanding of the design and use of technologies which is of huge significant for the IS field. Studies have drawn from ANT theory and concepts and these have helped them discover new ways of analysing organisation change and development processes. For example, Marres (2004) revealed how ANT served as a useful insight for studying the democratic process facilitated by ICT and developed a conceptual framework and a methodological direction that helped explored the nature of the problem. Lee and Oh (2006) adopted ANT to examine the processes involved in setting up mobile standards. ANT helped them "to analyze the way in which actors form alliances and enrol other actors to support such alliances surrounding technology" (Lee and Oh, 2006, p. 177). Gao (2005) used ANT to study the social-technological construction of chain's strategy for telecommunication market transformation and concluded that ANT was a suitable theory for exploring the nature of the situation. Allen (2004) employed ANT to study the evolution of personal digital assistant.

ANT concepts have also been used to study the technology development and adoption. For example, Faraj et al. (2004) adopted the concepts of inscription, translation and framing to examine the evolution of web browsers; while one of the early views of ANT (Walsham, 1997) demonstrated how ANT had been used in IT development and infrastructure standards. Tatnall and Jerzy (2003) used the concept of translation to interpret what actually derives older people to adopt ICT. In a more recently study, Andrade and Urquhart (2010) drew on ANT (the process of translation) to explore the different stages of ICT aimed to help the development in the rural area of the Peruvian Andes.

ANT is used in this study because "it is based on no stable theory of the actors; rather it assumes the radical indeterminacy of the actor" (Callon, 1999, p. 181). Most adoption theories, such as TAM, look at the adoption as a one-off decision-making event and are not able to reflect the dynamic, evolutionary and the interplay aspects of adoption from a process point of view. These theories also do not challenge the technology implementation in a social setting; instead, the theory like Rogers' (1995) DOI accepts the technology the way it is and relies heavily on early adopters or opinion leaders for its diffusion (Andrade and Urquhart, 2010). Traditional adoption theories have permanent separation between technology and the social world (Akrich et al., 2002). Monteiro and Handset (1996) contend that any theoretical framework that makes prior distinctions between the technology and the social world is unlikely to keep its focus on the aims of social arrangements regardless of whether it is a means to achieving the technical or the social. Although Orlikowski's (1992) structuration theory can be used to study how new technologies are adapted in organisations, it pays less attention on how it is conceived, created and recreated (Faraj et al., 2004). Orlikowski's structuration theory also pays less attention to the roles played by the technology if not completely neglected (Kallinikos, 2004). ANT allows for an examination of the interplay of both social and technical actors 
(Latour, 1987). Furthermore, it is argued that technology cannot be predicted in clear terms and any theory that assumes that this is possible cannot allow the researcher to trace the negotiation process that takes place during technology implementation (Callon, 1991, Akrich et al., 2002).

The application of ANT concepts in different contexts and the attention the theory had drawn to its self-demonstrates how powerful and relevant it is as a theoretical lens. According to Hanseth et al. (2004), using ANT to examine the development and use of communication and information technology may become more relevant in understanding the evolutionary process involved.

The key ANT concepts of inscription, translation, framing and stabilisation are adopted for the study. These key concepts are explained below.

\section{Inscription}

Inscription is a process whereby actors form values towards the technology or the extent to which the innovators determine or formulate what the technology or its functionalities are or should be (Faraj et al., 2004). Inscription is often influenced by an organisation's beliefs, previous patterns of IT use and expectations over what the technology is about and can do (Callon, 1991).

\section{Translation}

The process of aligning numerous interests and beliefs of different actors with that of the key actors within the network (Callon, 1986). It involves understanding how actors seek the interest of other human actors or convince others, directly or indirectly, to adopt new technologies (Callon, 1986). It is important to note that in a situation where there are many key actors attempting to make sure that other actors support their claims, Sarker et al. (2006, p. 54) argue that the researcher needs to select a key actor that from "whose perspective, it makes most sense in the describing the translation process". Also, considering the fact that a network may not be stable or be disintegrated at any time, the key actor may be different at different point in time during the process of translation.

\section{Framing}

According to Faraj et al. (2004) new technologies undergo alteration or change either because they require advanced features or an improvement upon their existing features, especially when adopted by lead users. This often allows new or different ways of using these technologies to emerge. Such technology may not be successful if users do not believe in the way they are designed and used (Faraj et al., 2004). Framing recognises that actors not only inscribe beliefs, interests and values over technology, but such values may be dissimilar and detached from one another (Orlikowski and Gash, 1994).

\section{Stabilisation}

Stabilisation is where the relevant actors consider the problem as being solved (Bijker et al., 1989). Stabilisation of technology does not evidently mean that technology is not amendable. Indeed, technology and business processes might change or adjust over time or as Bijker et al. (1989) put it "closure by redefinition of a problem" which leads to inscription again.

These four concepts are used to help unveil and explain the dynamic process and the interplays of human and non-human actors in shaping emerging ICT adoption.

\section{ICT's adoption} in SMEs

67


ITP

27,1

68

\section{Research methodology}

The majority of IT adoption studies have focused on confirmatory statistical techniques (Silva, 2007; Schwarz and Chin, 2007). While these approaches are well recognised, it is argued by Silva (2007) that IT adoption research requires more explanatory theories and methods that can help explain and understand the phenomena. The qualitative approach serves as a useful alternative and provides rich insights and results (Lee, 2003). This study adopts a qualitative approach in an attempt to obtain rich and in-depth understanding on the dynamic nature of ICT development and adoption in UK service SMEs. The service sector has expanded rapidly in recent years and is considered as the main source of job creation, and often compensates for job losses in the manufacturing sector (Sheehan, 2006). The growing significance of the service sector suggests that efforts to improve living standards, jobs creation and boosting the economy increasingly depend on the service sector (Sheehan, 2006). Since qualitative research emphasises the discovery and explanation of people's experiences, purposive random sampling was adopted to identify service in the data collection. The logic behind purposeful sampling is to select units of analysis (individual based) that enable the researcher to make a reasonable comparison in relation to research objectives and not for statistical generalisation (Mason, 1996). Snowball sampling complimented the purposeful random sampling because participants introduced the researcher to other key informant that also participated in the interviews.

The research employed a two-round data collection process using unstructured (first round) and semi-structured (second round) interviews. The first round of interviews followed a fairly unstructured pattern which provided an open, flexible, experimental and revealing pattern of studying complex interactive situations in the research context. The purpose of the first round of the interviews was threefold. First, to understand the current state of emerging ICT adoption in small service SMEs in order to have a broad and unconstrained view; second, to test the applicability of the key ANT concepts: inscription, translation, framing and stabilisation; third, to identify the key actors and their roles involved in the adoption. The inclusion of these four concepts in this study was based on the outcome of the initial applicability of these concepts. In the first round, the interviewee sample was generated from an online database and 65 participates were contacted randomly, of which 11 participants agreed to be interviewed. The main question asked during the interview was "how does your company constantly keep up with the emerging ICT to improve business performance and competitiveness?". This triggered other probing questions during the interviews. Most interviews were carried out with SME managers. Findings from the first round of the unstructured interviews helped to develop the semi-structured interview questions for the second round of data collection.

In the second round, 15 semi-structured interviews were conducted with a range of key human actors identified from the first round of interviews that were stakeholders of ICT adoption in service SMEs. They included small business manager; government agencies that provide training and support to SME managers, SMEs consultants, IT experts and IT vendors. The key questions asked were related to their current ICT adoption status, the process involved in ICT adoption based on the ANT concepts, actors involved, their roles and activities at each stage of adoption. Table I provide a summary of interviewee's profile.

All the interviews lasted for about 45 minutes to one hour. The method for data analysis were thematic analysis. This is a method of searching, identifying, analysing and reporting themes that are important to the phenomenon being investigated (Braun and Clarke, 2006). The data analysis process involved six stages as described in Figure 1. 


\begin{tabular}{|c|c|c|c|c|}
\hline $\begin{array}{l}\text { Interview } \\
\text { participants }\end{array}$ & Position & $\begin{array}{c}\text { Company } \\
\text { size }\end{array}$ & Service & in SMEs \\
\hline $\mathrm{A} 1$ & Managing director & 30 & Security & \\
\hline A2 & Manager & 25 & Internet marketing and advertising & \\
\hline A3 & IT support staff & & & 69 \\
\hline $\mathrm{A} 4$ & IT support staff & & & OY \\
\hline A5 & Manager & 9 & Social media/consultancy & \\
\hline A6 & Manager & - & Social network provider & \\
\hline A7 & Managing director & 25 & IT Vendor/consultancy & \\
\hline A8 & Directors & & & \\
\hline A9 & Operational manager & 45 & Sales and distribution & \\
\hline A10 & Managing director & 80 & Construction & \\
\hline A11 & Manager & 5 & IT Vendor/consultancy & \\
\hline A12 & Manager & 52 & Business and Management/consultancy & \\
\hline A13 & Manager/IT support staff & 99 & IT & \\
\hline A14 & Manager & 8 & Accounting & \\
\hline A15 & Developer & 1 & IT and networking & \\
\hline A16 & Designer & 1 & IT & \\
\hline A17 & Test analyst & 245 & IT quality control & \\
\hline A18 & IT Designer/developer & 2 & IT & \\
\hline A19 & IT Developer & 1 & IT and networking & \\
\hline A20 & IT consultant & 11 & Consultancy & \\
\hline A21 & Government agencies & - & Education and training & \\
\hline A22 & Government agency & - & Education and training & \\
\hline A23 & Government agencies & & Education and training & \\
\hline A24 & Government agency & 22 & Support services & \\
\hline A25 & Government agencies & - & Support and advisory services & Table I. \\
\hline A26 & Manager & 102 & IT consultant/business supports/advice & Interviewee profile \\
\hline
\end{tabular}

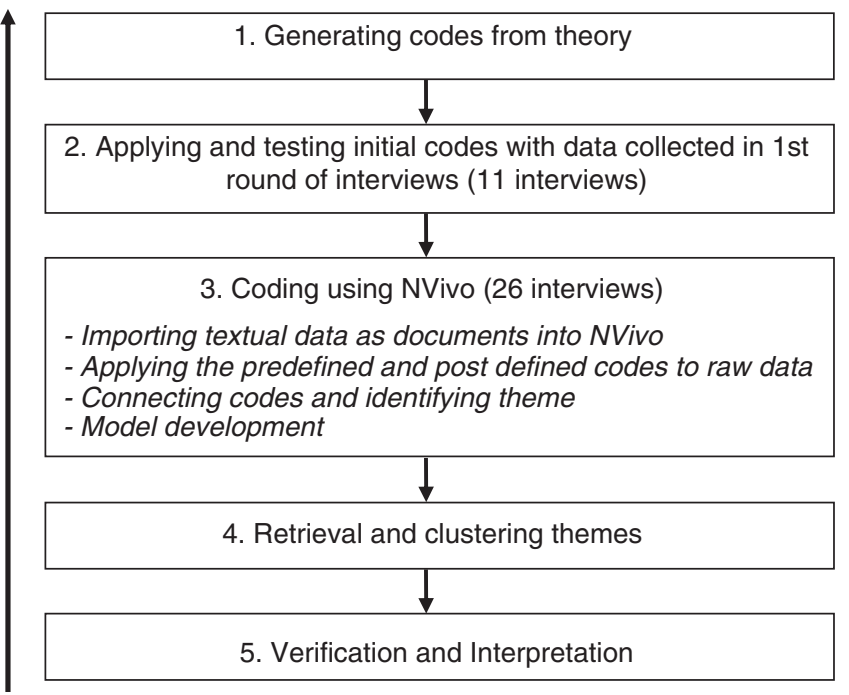

Figure 1. Data analysis process 
ITP

27,1

70

Stage 1: at Stage 1, the concepts (inscription, translation, framing and stabilization) which have been developed previously from the literature formed the bases for exploring the raw data. The definitions and characteristics of these theoretical codes were written in simpler terms using: code name, the definition of what the codes are, and the description of how to know when the theme associated with each code occurs. All of these became the basis for categorizing the raw data. The practical guide for coding the raw data are depicted in Table II.

Stage 2: to ensure that codes generated from theory would be applicable to the raw data, in Stage 2, the 11 transcribed interviews in the first round were manually coded into pre-defined categories. The reliability analysis was subsequently ascertained to ensure that the theoretical codes are credible and would be applicable to subsequent raw data. Following the preliminary coding process of the first round of the interviews, four judges (colleagues) were employed to relate both the pre-defined and post-defined codes to the categories to ascertain their reliability. The result of the reliability analysis shows that these concepts score more than 70 per cent bench mark proposed by Miles and Huberman (1994).

\begin{tabular}{ll}
\hline Code name & Definition \\
\hline Inscription & $\begin{array}{l}\text { How actors formulate emergi } \\
\text { ICT that protects their intere }\end{array}$ \\
& \\
Translation & $\begin{array}{l}\text { How various actors seek the } \\
\text { interest of others to support } \\
\text { their claims or assumptions } \\
\text { about the emerging ICT? }\end{array}$
\end{tabular}

Framing

How various actors support a certain version of emerging ICT?

Stabilisation How key actors institutionalised the accepted version of the emerging ICT and why change subsequently occurs?
Table II.

Practical guide for coding the raw data
Description for coding

To identify why and how the assumptions of the emerging ICT are formulated

1. This is indicated when a problem or a need for emerging ICT is identified and assessed

2 . This is how ideas are defined and specified To identify the practices of actors who assign responsibilities and the consequences of such actions

1. This is indicated when actors outsource project and delegate roles

2. This is indicated when misunderstanding of interests (conflict) arises and subsequently how consensus among actors is reached To identify the practices of actors assessing validity

1. This is indicated when actors claiming validity engages in modification of the emerging ICT

2. This is indicated when actors claiming validity involve in testing the emerging ICT

To identify the practices of actors involved in the implementation and use of the emerging ICT

1. This is indicated when such activities like training, for the emerging ICT occurs

2. This is indicated when learning for the emerging ICT occurs

3. This is indicated when To identify the impact of using emerging ICT to adapt the work process

1. This is indicated when emerging ICT is used to makes work easier

To identify the practices that may subsequently lead to the need for new ICT

1. This is indicated when change occurs 
Stage 3: all the transcribed data (26 interviews) were imported into NVivo. NVivo was used to facilitate the analysis because of the volume of data involved. This helped in the application of codes to the raw data.

Stage 4: data were retrieved from NVivo in Stage 4 and were conceptually clustered (see Table III). Bearing in mind that verification in qualitative research is always an ongoing process, further verification in Stage 5 implied other reliability and validity checks. This include presenting the codes and quotes to an expert in this area who compared the quotes against the codes and themes The data analysis process in Figure 1 is part of the research design which reveals how data were analysed, verified and reported.

Stage 5: inter-rater reliability of the entire data coded using percentage agreement (Boyatzis, 1998) were conducted which enabled a number of colleagues to rate the quotes against the codes and themes that emerge. This approach was used because data coded were nominal and required absence or presence judgments by the coders. The reliability analysis for the scope of the study shown in Table III revealed over 84 per cent. This suppressed the 70 per cent benchmark suggested by Miles and Huberman (1994). Validated codes were further analysed and interpreted in this stage (see Section 4).

\section{Findings and discussion}

The findings presented in Tables IV and V depict the themes associated with the emerging ICT adoption process at each stage, their supporting cases. Boyatzis (1998) identified three methods of thematic analysis (data-driven approach, theory-driven approach and hybrid approach), we adopted theory-driven approach considering the fact that the concepts used in this study were initially derived from the existing theory (ANT). Themes were clustered conceptually base on the characteristics of the four

\begin{tabular}{lll}
\hline Coding theme & \multicolumn{2}{c}{ Reliability - level of agreement } \\
Number of judges & First two judges & Second two judges \\
\hline
\end{tabular}

ICT adoption process

4

$88 \%$

$85 \%$

Total supporting cases

iCT adoption

stages and key activities

Supporting cases

A1, A2, A4, A5, A9, A10, A11, A13, A14, A24

Stage 1: inscription

Problem assessment

Concept generation

and evaluation

Concept specification

Stage 2: translation

Role delegation

Alignment of interest:

Stage 3: framing

Product trial

Product modification

Stage 4: stabilisation

Adaptation

Impacts assessment

Problem redefinition
A2, A5, A13

A4, A9, A10, A11, A24

A1, A5, A14

A5, A9, A19

A1, A15, A17, A20

A2, A5, A9, A18, A20

A1, A9, A13, A19

A1, A2, A13, A14, A24

A1, A7, A24

A5, A6, A15
$10 / 26$

$$
\text { A1, A9, A15, A17, A19, A20 }
$$

A1, A2, A5, A9, A13, A18, A19, A20

$8 / 26$

A1, A2, A5, A6, A7, A13, A14, A15, A24

$9 / 26$
ICT's adoption in SMEs

71
Table III. Reliability analysis
Table IV.

Key activities at each stage of emerging ICTadoption process with supporting cases 
ITP

27,1

\section{2}

Concept generation and

evaluation:

Concept specification:

Code 2: translation

Role delegation

Alignment of interest

Code 3: framing

Product trial

Product modification

Code 4: stabilisation

Adaptation

Impact

Table V.

Key activities at each stage of emerging ICTadoption process with supporting evidence

Problem redefinition
Samples of supporting evidence

"looking at the future projections and ...now looking at the past, the company actually sat down and evaluated their business process, evaluated or reviewed what they hope to evolve into"(A13)

"We come up with a concept and the requirements, then we generate the ideas, we evaluate the ideas and then plan for other people that will join the project" (A9)

"The smart patrol is actually built around our specification and that is what we asked for" (A1)

"When you have got a problem like that, a middle company or a middle man would help you because I am not sure what I wanted. So I need to talk to somebody that actually specialises in it, so he can sort my brand...they would know because I can't do that myself" (A19)

"In respect of the smart patrol, it was very new and people who did it for us were IT specialists. They find it easy to work out, but their perception of what we wanted was different. So we told them to remove some part. Now it is exactly what we wanted" (A1)

"[...] what we do is for example, with the CRM System, [is] we try them internally, basically it is just one person, myself, and we also try it with three of our clients externally" (A5)

"[...] the solutions have been developed which is the solution by SAPs [...] However, when we identify our interests and selected that as the final product, it involved some customization" (A13)

"Every day new changes come [...] and sometimes we are a bit behind learning the skills [...." (A14)

"[...] we had like 25 people working for us and we were turning over a million. With that size, comes a lot of complications, headaches and now one person $[\ldots]$ can manage all the task with these technologies" (A7)

"When you are an entrepreneur you need to be able to do things that may fail. Failure is not necessarily a failure. [you] just understand your mistakes and then change them and continue to evolve. You must always have that mentality"(A6)

concepts of ANT adopted in the study shown in Table V. It shows the identified activities at each stage of adoption. The findings presented here are based on narratives of participants, ANT concepts and the relevant literature.

\section{Identification of relevant actors}

The findings that the development and adoption of emerging ICT in SMEs involved a variety of actors and a number of stages because of its complexity and unpredictable nature. The small business managers, as the emerging ICT's adopter and decision maker, are the competing actor that ensures that other actors support their claims in technology development and deployment (Sarker et al., 2006). Therefore, they are identified as the key actor in this context. The identification of the SMEs as the key actor made it possible for the enrolment of other internal and external actors in this 
research. Interviews with the small business manager helped to identify other internal actors (employees who may have the potential for contributing in making effective emerging ICT decisions) and external actors (e.g. IT experts, IT vendors consultants, government agencies, customers, emerging ICT and standards) who constitute an integral part of the network (see Figure 2). SME managers took up the role of the most visible actor representing the network. Therefore, to understand how "the key actors" are being challenged in the process, efforts were made to understand the situations that shaped the entire process; otherwise deep insights about the interactive nature involving the conflicting forces characterised by the continuous change process

\section{Inscription stage}

In this stage, "you [must] have a clear idea who your stakeholders are. This also includes everybody in the organisation. You may bring in potentially other expertise that may have not been included" (A11). Recent studies (Lawrence, 2010, Kannabiran and Dharmalingam, 2012) in a small business context have reported the challenges associated with ICT adoption, which include limited financial resources, poor knowledge of ICT that impede key actors from keeping up with new technology applications. These increase the level of dependencies that key actors have on the external entities.

Emerging ICT adoption is associated with some degree of uncertainty. Key actors are considered innovation conscious when they try to develop their own ideas and specification (Swanson and Ramiller, 2004, Teo et al., 2011). In practice, a question may be raised as to how key actors gain knowledge of emerging ICT. Our analysis suggests that most emerging ICT is driven by the enthusiasm of key actors that engage in continuous negotiation with others in the process. For example, one manger explained that "we always bring the business intelligent together, what we call those imaginary aspects into it [...] like a product development, business case, everything from

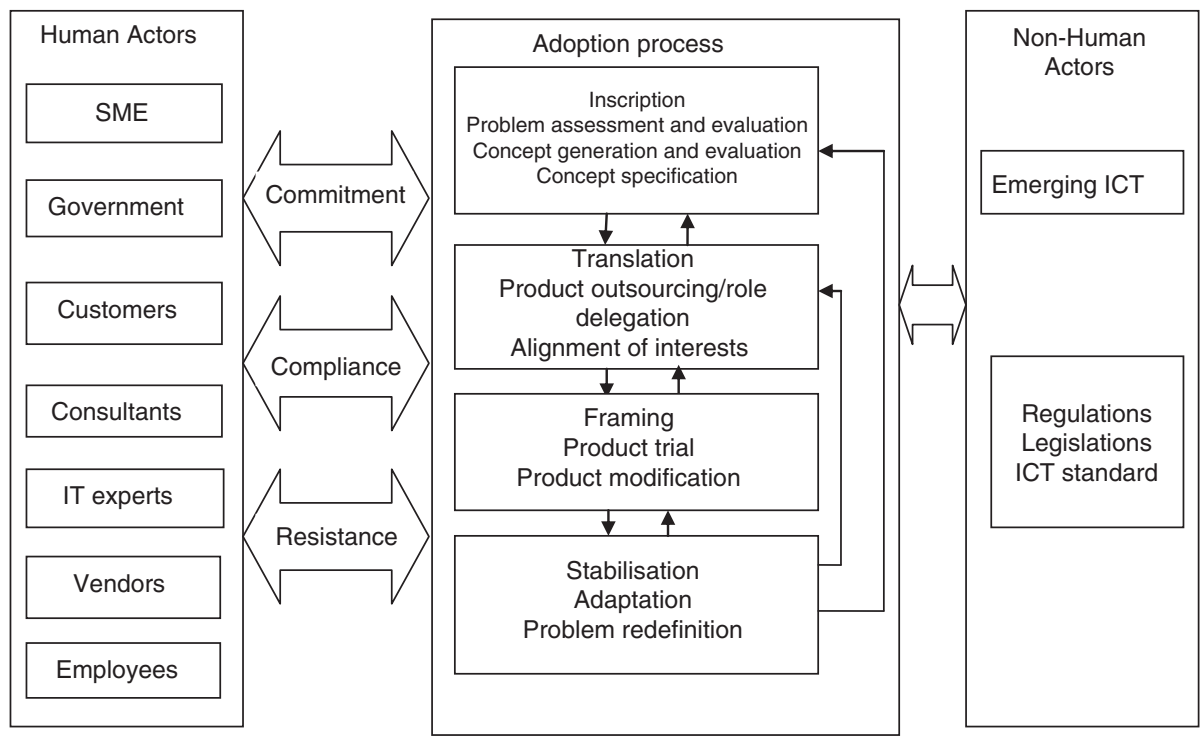

\begin{abstract}
would not be gained.
\end{abstract} .

\section{ICT's adoption}

in SMEs 
ITP

27,1

branding to what it should be called [...]" (A5). This was further supported by one of interviewees: "As a CEO I may have a couple of young graduates and you say to them, guys, I have got this business problem go and find me a solution. So you will be the innovator deriving ideas through the organisation" (A12).

According to one of the managers, emerging ICT adoption "requires incorporating the inputs of other external actors; you [must] bring in the expertise of informed internal and external stakeholders" (A11). Key actors assess the technical options and analyse the surrounding situations. This is one of the critical business problems key actors face when a technology application is considered in order to help solve a problem. The outcome of this leads to concept generation, which entails generating ideas/concepts and evaluating the ideas specified in key actors' terms. "Looking at future projection and $[\ldots]$ now, and looking at the past, the company actually sat down and evaluated their business process, reviewed where they hope to evolve into and based on that, try to map that into the current solution $[\ldots]$ and found that what is envisaged $[\ldots]$ might not be possible for the current solution $[\ldots]$ to properly handle the companies processes" (A13). Teo et al. (2011) contend that technology will be useful if it serves the needs of both the internal and external users. Non-human actors, such as government regulation, will also play a role in this stage as one participants indicated that we "need to use new technology to adhere to health and safety policies and also be transparent to our clients" (A1). At the inscription stage, a considerable amount of effort is made to identify actors that might be relevant to establishing the ICT and its use. "Yes I always say that the technical knowledge is new to me except operating this keyboard etc. Of course, if there is any special area [relevant to our business], we have to consult all the relevant people who know the technology and that will put the system right" (A14). In support of this, numerous studies suggest that key actors tend to exhibit greater closeness to external actors. For example, Herstatt and Hippel (1992) and Gottfrisson (2011) recognised the importance of external actors in ICT adoption and suggest that SMEs can be more influenced by external actors compared to large organisations. In addition, Simpson and Docherty (2004) also found that the capacity for SMEs to strive for external support is stronger compared with large organisations. The finding suggests that key actors rely heavily on the external forces such as government agencies and customers, who in most cases support or challenge their decisions. One of the implications of this is that the activities of key actors are not certain as they are challenged at the earliest possible stage. Therefore, at inscription, the key actors use information about the consequences of the ICT generated internally and externally to make decisions on whether to adopt or adapt the emerging ICT. Akrich et al. (2002) point out that actors that intervene to make decisions are so many and so intertwined with each other that at the end of the decisions, it is difficult to identify to whom the result should be attributed.

\section{Translation stage}

In most cases, ICT is outsourced, and roles delegated to third parties, which may not be directly controlled by the key actors. This study reveals that, at this stage, key actors' decisions may or may not be supported when different external actors meet because the goals or perceptions of these actors in most cases are different. Most times the support that these external actors provide depends on how much they conform to key actors' emerging ICT interests. Firms that have interests and assumptions leads to greater alignment of interests. However, the study finds that alignment is difficult to achieve and often results in unstable commitment from different actors involved in establishing 
emerging ICT because the backgrounds and perceptions of actors are different. "[...] we pay IT people to provide the service, and if they cannot give us the service, we invite other companies, it is as simple as that" (A9). Actors may have diverse or conflicting views about what the intended ICT should be. For example, key actors often have preconceived ideas, which may or may not, be realistic. One interviewee (IT Vendor) mentioned that: "most times the issues we usually have is that [SMEs] [...] have a fixed idea of what they want and I just don't want to sell anything [they want], I don't do what they want me to do. I take into consideration what is the market trendy. Most times we tend to have conflicts there" (A18). On the contrary, others may be more interested in what they can gain commercially instead of what would satisfy the needs of the key actors: "IT consultants are not independent. They are trying to sell you what they want to sell to you" (A11). This has been supported by previous study. For example, Chibelushi and Costello (2009) found that one significant challenge facing most small businesses is linked to a number of untrustworthy and non-proficient set of consultants that offer advice to them. Hence, despite the potential of emerging ICT, the long-term feasibility often remains uncertain because of the enormous challenges faced by actors along the adoption process. Second, involving diverse actors may not always promote new ICT; rather, it may hold back key actors from engaging in ICT adoption/development. One of the advantages of this is that those key actors, that are innovative, may only consider developing and/or adopting any new innovation when it is conducive and in line with the actual organisation's and other actors', such as customers, requirements. Therefore, alignment is important at this stage in order to realise the set objectives of key actors.

\section{Framing stage}

The concepts and specifications may have existed in verbal description, but at this stage, they are transformed into physical objects. Garud and Rappa (1994) note that a firm that establishes a standard influences the way innovations are designed and used because the more a piece of technology conforms to the required evaluation criteria, the more valuable it is to the users. As stated earlier, the views of the key actors, others and the IT experts may be different and often results in resistance around ICT development and use. In line with this, evidence from the semi-structured interview suggests that emerging ICT may not be always perfect; rather the efforts on the part of key actors to apply the technology always reveal problems which are not anticipated. Standards are essential in ICT because they are the basis for increasing return if appropriate emerging ICT is institutionalised. Our evidence suggests that emerging ICT often undergoes rigorous functional testing. Product testing and modification is a important activity that various actors including customers, key actors and others undertake in order to ensure that the features of the new ICT not only are workable but also reliable. For example, one SME manager mentioned that "[...] the solutions have been developed which is the solution by SAPs [...] However, when we identified our interests and selected their solution as the final product, it involved important customization to meet our business need" (A13). Similarly, Attaran and Attaran (2002) emphasise that customisation of ICT usage enables an organisation to create optimal and efficient information resources. In most cases, customisation is made in order to enhance key actors' interests. This requires constant negotiation and confrontation between the key actors and other actors such as IT experts. Emerging ICT standard requires the cooperative effort of key actors, government legislation, customers and others who learn and reconfigure the new ICT
ICT's adoption in SMEs

75 
ITP

27,1

76 to suit the key actors' request. One of the implications of this is that involving various actors in adoption and reconfiguration of emerging ICT may help key actors in introducing an application that may be unique and difficult for competitors to replicate.

\section{Stabilisation stage}

The unpredictable nature of the business environment has made organisation planning for ICT adoption and/or development to follow an unpredictable path. Organisational characteristics may be stable at one point, but there is no guarantee it will continue to be stable over time. The general thread observed running through the findings is that adoption of emerging ICT does not always produce the expected results. Stability of IT is constantly negotiated as a social process of aligning diverse interests. It depends on the ability of the key actors in aligning their interests to other actors' own values and interest (Hanseth and Monteiro, 1997). The finding suggests that aligning technology with business processes is crucial. The roles of the actors at this stage were to learn and adapt the emerging ICT: "When you implement the program, there needs to be training, adequate training and on-going support as well, until people feel confident" (A24). This lens support to Litwin (2011) who points out that adoption and diffusion of ICT requires the understanding of how humans and technology interact since it has been revealed that many of its benefits depend on the interplay of the ICT and the users. Evidence collected reveals that new ICT does not instantly improve the activities of those that engage with it but often interrupts them. Since employees are users of the new ICT, most times they dictate problems not discovered during the initial stages or avoid using the new ICT. One of the challenges faced during adaptation is that the internal organisation actors (employees) in most cases are not always involved in the emerging ICT adoption decision making. One participant revealed that "as the operations manager, I don't need to ask the employees, I am in a position to make that decision because I know what will benefit the business" (A9). Employees sometime were dissatisfied with the new ICT and remained adamant to change as highlighted by one participant that "[...] another challenge was staff resistance" (A13). The findings reveal that most times employees are neglected from taking part in ICT decision making.

Stabilisation of emerging ICT may be witnessed where the new technologies impact on and improve organisational performance and processes significantly (e.g. improve efficiency, business process, or communication). However stability of the new technology is not steady. As the business environment remains unstable, so do firms constantly change or improve their processes especially where the impact of the emerging ICT is not satisfactory or new problems emerge. Though SMEs deem stabilisation extremely crucial, technologies development does not stabilise. Our study suggests that while the technology advances, organisations always look for new technology applications that meet their changing needs. One participants highlighted that "we are already started looking for the other technology. Probably because there are other things that may be better [...] I am looking at the next evolvement of the whole process really" (A1). Walden and Browne (2009) argue that ICT evolves rapidly, and it is not clear; there would be a time when stable equilibrium would be achieved. Adoption of emerging ICT in small service businesses happens through a continuous and repetitive flow of activities. This process is dynamic which underlines the mutual shaping of actors and reveals the situations where the key actors move from a homogenous isolated entity to reformulated group entity (Millerand and Baker, 2009). 
Based on ANT concepts and our empirical evidence collected from interviews, a research framework is formulated and presented in Figure 2. The framework depicts the stages, actors, key activities involved in the emerging ICT adoption. The framework shows various actors that the study identified, the activities and the interactions that actors engage in within each stage, and the dynamic interplay between stages.

The proposed framework makes important contributions to the ICT adoption research. First, the framework demonstrates the emerging ICT adoption from a process view in the context of SMEs by incorporating the key concepts of ANT into four dynamic stages of inscription, translation, framing and stabilisation. The four-stage framework attempts to show the complexity and dynamics involved in ICT adoption in a simple form when various actors are involved in ICT development and deployment.

Second, the framework identifies and includes a diverse range of actors (human and non-human) involved in the dynamic process and provides an important base for further analysis of the actors' roles and influences. ICTs adopts in SMEs are strongly influenced by external actors either human or non-human. The findings reveal three influences associated with human actors (see Figure 2), namely commitments, resistance and compliance. A number of studies have pointed out that managers are the main source of organisational change and these actors often initiate and implement changes in response to perceived opportunities to improve business processes (Orlikowski, 1996). This lends support to the findings of this study. It suggests that at the inscription stage, when there is no commitment, support or enthusiasm from other actors, which should be an integral part of the decisions at inscription, negotiation appears to be difficult and takes longer than required at the translation stage. Therefore, innovative small business managers as the key actors should have the commitment to adopting emerging ICT and make the adoption when they agree with the views and requests of other actors in the network. The finding suggests that commitment may be most beneficial outcome in building effective emerging ICT. However, there is always resistance in the process and it may occur at any stage. Resistance occurs because various actors including small business managers often lack the confidence of the other actors in the process. The study reveals that key actors are in the midst of the innovators; however, to negotiate for ICT standard is an exceedingly difficult task when diverse actors are involved because of different perceptions inscribed on it. Compliance assists to accomplish the request of the key actors; however key actors often lack the compliance from other actors. Although the key actors may comply since they lack the knowledge and ICT skills, in most cases they always see other information as an opportunity to challenge the views of IT experts, vendors and others in the process. It is important to note that compliance does not mean that SMEs will not experience further adoption decisions because of the changes in the business environment which may require new commitment. These dynamic influences not only allow SMEs to be more innovative, but also make them learn from their previous mistakes/experience to improve their new adoption decisions. These influences occur at one or more stages and remain an ongoing improvisation that actors try to make sense of and act coherently (Orlikowski, 1996).

Third, the framework provides a mechanism of showing the reiterative and no linear nature of ICT adoption process in SMEs. It shows a process that can reiterate along with the technology development. As a result of each adoption cycle, the level of ICT applications is also improving incrementally or radically over time. The framework reveals that the pattern of ICT adoption in a small business context
ICT's adoption in SMEs 
ITP

27,1

78

is not a straightforward one-off event. The stages in the framework may become hindered at any point if there are conflicting views or challenges among various actors; this leads to withdrawal, or re-evaluation, of some or all of the adoption activities. The dynamic negotiation process in the framework necessitates actors to shift forward and backward between stages. The adoption stages include a distinctive iterative phase with the activities occurring continually over time during the lifecycle of the small businesses where diverse actors are involved. It also offers a systematic way to analyse critical success factors in association with the stage and the overall process.

\section{Conclusions and implications}

This study attempts to advance ICT adoption research and practice by examining emerging ICT adoption in SMEs from a dynamic process perspective based on the ANT. In doing so, the findings demonstrate that ANT has helped to understand the dynamic and interactive nature of emerging ICT adoption. The outcome of our study is the presented framework which depicts the adoption from a dynamic process perspective based on the four ANT concepts: inscription, translation, framing and stabilisation. The study has identified the key activities associated with the adoption process. These key activities include: the problem assessment and evaluation, concept generation and evaluation, concept specification, product outsourcing/role delegation, alignment of interests, product trial, product modification, adaptation, impact and problem redefinition. These activities help to illustrate that the adoption of emerging ICT in a small business context is not constant, straightforward and certain; instead it is dynamic, interactive and an ongoing process. This is because decisions are not made by a single individual; instead, such decisions are influenced by numerous other actors whose perceptions and views may differ. As explained in the last section, we believe that the proposed framework provides a useful analytical tool to illustrate the dynamic process view of ICT adoption and the emphasis on the interplay of key actors with other actors in influencing the dynamic adoption process. Our attempt is a step towards developing new ways of examining and understanding the interplay between constant ICT advancement and the human actors in the network, especially, how the actors are influenced or influencing the technology development for business innovation, competitive advantages and improved organisational performance.

Emerging ICT adoption has moved from a simple adopters' participation process to involving various actors that constantly interact and influence the process. The study confirms that small business managers can influence as well as be influenced by the technology and other human actors. In addition, it reveals that these actors especially the innovative ones are at the forefront of initiating and influencing the technology development and adoption. Adoption is a complex process requiring significant attention and interactions among all actors. These actors are both internal and external to small business and impact on the adoption success at each stage. Their role and extent of impact vary at each stage and the framework can assist the analysis of the roles of actors at each stage and the critical success factors.

In the design and implementation of ICT, previous studies pointed out that IT experts have always relied on methods that are structured in order to get information requirements from managers and the users of the technology (Orlikowski and Gash, 1994). However, Hanseth and Monteiro (1997) have argued that these methods do not pay sufficient attention to assumptions, expectations, values and beliefs and how these may differ from diverse actors including the SME managers and those that build the technology. Therefore, the study may be useful to the actors that are involved in the 
development of ICT so that they can better understand how their values, knowledge expectations and interpretation of the emerging ICT and the organization change relate or differ to the small business manager's interest. Those that positively influence the adoption can use the framework to make estimation of possible values and interest that others may attach in the process.

Emerging ICT adoption requires alignment of external actors to that of SME managers' interests. IT experts, vendors, consultants, government support agencies and other actors involved in the process must focus their attention to the key actor's requirements to ensure the success. The framework may be useful to various actors in the process. IT experts, vendors and especially, consultants who may not have any specific organization context they operate can use the framework and the associated activities as a guide to learn and understand the extent that their knowledge and interpretation of the emerging ICT relates to the key actors' views and interests. Also, by involving these actors, small business managers can make better decisions by reviewing and analysing their surrounding environment and anticipate what will be the impact on the entire business networks that they operate. This is likely to improve the chance of coping with unanticipated changes.

Often in qualitative research, the size of the sample used are limited. These limitations require caution for the generalisation of the findings. The framework can be further validated across a wider population using mixed methods combining qualitative and quantitative approaches. Therefore, further studies can collect and collate a larger number of data to allow a more reliable generalisation. ICT adoption is an ongoing action and managers do not rely on a single system, due to constant changes in business environment and technology advancement. Instead they rely on a number of technology applications, which constitute multiple types of emerging ICT, to accomplish their tasks. Therefore, the study did not focus on a specific type of emerging ICT as our aim is to develop a framework that can be applied to examine different types of emerging ICTs in SMEs. While this may be considered as a limitation, this generic framework would provide a sound basis for developing context specific framework in the future. For example, it can be further modified to analyse the adoption of a social networking system for promoting the business (such as Facebook page).

\section{References}

Akrich, M., Callon, M. and Latour, B. (2002), "The key to success in innovation part 1: the art of interessement", International Journal of Innovation Management, Vol. 6 No. 2, pp. 187-206.

Al-Natour, S. and Benbasat, I. (2009), "The adoption and IT artefacts: a new interaction-centric model for the study of user artefact relationships", Journal of Association for Information Systems, Vol. 10 No. 9, pp. 661-685.

Allen, J. (2004), "Redefining the network: enrolling strategies in the PDA industries", Information Technology and People, Vol. 17 No. 2, pp. 171-185.

Andrade, A.D. and Urquhart, C. (2010), "The affordances of actor network theory in ICT for development research", Information Technology and People, Vol. 23 No. 4, pp. 352-374.

Attaran, M. and Attaran, S. (2002), "Collaborative computing technology: the hot new managing tool", Journal of Management Development, Vol. 21 No. 8, pp. 598-609.

Bagozzi, R.P. (2007), "The legacy of the technology acceptance model and a proposal for a paradigm shift", Journal of the Association for Information Systems, Vol. 8 No. 4, pp. 244-254.

Barrett, M., Grant, D. and Wailes, N. (2006), "ICT and organisation change: introduction to special issue", The Journal of Applied Behavioural Science, Vol. 42 No. 4, pp. 6-22.
ICT's adoption in SMEs

79 
ITP

27,1
Bijker, W.E., Hughes, T.P. and Pinch, T. (Eds) (1989), The Social Construction of Technology Systems: New Direction in the Sociology and History of Technology, Maple-Vail Inc, York, PA.

Bostrom, R.P., Gupta, S. and Thomas, D. (2009), "A meta-theory for understanding information systems within social technical systems", Journal of Management information Systems, Vol. 26 No. 1, pp. 17-47.

Boyatzis, R. (1998), "Transforming qualitative information: thematic analysis and code development', Sage Publication Ltd, London.

Braun, V. and Clarke, V. (2006), "Using thematic analysis in psychology", Qualitative Research in Psychology, Vol. 3 No. 2, pp. 77-101.

Callon, M. (1986), "Some elements of a sociology of translation: domestication of the scallops and the fishermen of the Brieuc Bay", in Law, J. (Ed.), Power, Action and Belief: A New Sociology of Knowledge?, Routledge, London, pp. 196-223.

Callon, M. (1991), “Techno-economic networks and irreversibility”, in Law, J. (Ed.), A Sociology of Monster: Essays on Power, Technology and Domination, Routledge, London, pp. 132-161.

Callon, M. (1999), “Actor-network theory-the market test”, in Law, J. and Hassard, J. (Eds), Actor Network Theory and After, Blackwell Publishing, Oxford, pp. 181-195.

Callon, M. and Latour, B. (1981), "Unscrewing the big leviathan: how actors macro-structures reality and how sociologists help them to do so", in Kcetina, K. and Cicourel, A.V. (Eds), Advances in Social Theory and Methodology: Toward an Integration of Macro and Macro-Sociology, Routledge, London, pp. 277-303.

Chibelushi, C. and Costello, C. (2009), "Challenges facing W. Midlands ICT-oriented SMEs", Journal of Small Business and Enterprise Development, Vol. 16 No. 2, pp. 210-239.

Elbanna, A.R. (2007), "Implementing an integrated system in a socially dis-integrated enterprise: a critical view of ERP enabled integration", Information Technology \& People, Vol. 20 No. 13, pp. 121-139.

Faraj, S., Kwon, D. and Watts, S. (2004), "Contested artifact: technological sense making, actor networks and the shaping of the web browser", Journal of Information, Technology and People, Vol. 17 No. 2, pp. 186-209.

Gao, P. (2005), "Using actor-network theory to analysis strategy formation”, Information Systems Journal, Vol. 15 No. 15, pp. 225-275.

Garud, R. and Rappa, M.A. (1994), "A social-cognitive model of technology evolution: the case of cochlear implants”, Organisation Science, Vol. 5 No. 3, pp. 344-362.

Gottfrisson, P. (2011), "How small companies generate ideas for new services", International Journal of Business and Social Science, Vol. 2 No. 10, pp. 101-111.

Hanseth, O. and Monteiro, E. (1997), "Inscribing behaviour in information infrastructure standards", Accounting, Management and Information Technologies, Vol. 7 No. 4, pp. 183-211.

Hanseth, O., Aanestad, M. and Berg, M. (2004), "Guest editor' introduction: actor network theory and information systems. What's so special?", Information, Technology and People, Vol. 17 No. 2, pp. 116-123.

Herstatt, C. and Hippel, E.V. (1992), "From experience: developing new product concept via the lead user method: a case in a low-tech field", Journal of Production Innovation Management, Vol. 9 No. 4, pp. 213-221.

Kallinikos, J. (2004), "Farewell to constructivism: technology and context-embedded action", in Avgerou, C., Ciborra, C. and Land, F. (Eds), The Social Study of IT, Oxford University Press, Oxford, pp. 140-162.

Kannabiran, G. and Dharmalingam, P. (2012), "Enablers and inhibitors of advance information technologies adoption by SMEs: an empirical study of auto ancillaries in India", Journal of Enterprise Information Management, Vol. 25 No. 2, pp. 186-209. 
Latour, B. (1987), Science in Action, Harvard University Press, Cambridge, MA.

Latour, B. (2005), Reassembling the Social: An Introduction to Actor-Network-Theory, Oxford University Press, Oxford.

Lawrence, J. (2010), "The factors that influence adoption and usage decision in SMEs: evaluating interpretive case study research in information systems", The Electronic Journal of Business Research Methods, Vol. 8 No. 9, pp. 51-62.

Lee, H. and Oh, S. (2006), "A standards war waged by a developing country: understanding international standard setting from the actor-network perspective", Strategic Information Systems, Vol. 15 No. 4, pp. 177-195.

Lee, Y. (2003), "The technology acceptance model: past, present and future", Communication of the Association of Information Systems, Vol. 12 No. 50, pp. 752-780.

Litwin, A.S. (2011), "Technology change at work: the impact of employee involvement on the effectiveness of health information technology", Industrial and Labour Relations Reviews, Vol. 64 No. 5, pp. 863-888.

Marres, N. (2004), "Tracing the trajectories of issues, and their democratic deficits on the web: the case of development gateway and its doubles", Information Technology and People, Vol. 17 No. 2, pp. 124-149.

Mason, J. (1996), Qualitative Researching, Saga Publication, London.

Miles, M.B. and Huberman, A.M. (1994), Qualitative Data Analysis: An Expanded Sourcebook, Sage Publication Ltd, Thousand Oaks, CA.

Millerand, F. and Baker, K.S. (2009), "Who are the users? Who are the developers? Webs of users and developers in development process of a technical standard", Information Systems Journal, Vol. 20 No. 17, pp. 137-161.

Monteiro, E. and Handset, O. (1996), "Social shaping of information infrastructure: on being specific about the technology", in Orlikowski, W.J., Walsham, J., Jones, M.R. and Degress, J.I. (Eds), Information Technology and Change in Organisational Work, Chapman and Hall, London, pp. 325-343.

Orlikowski, W.J. (1992), "The duality of technology: rethinking the concept of technology in the organisations", Organisation Science, Vol. 11 No. 4, pp. 404-428.

Orlikowski, W.J. (1996), "Improving organisational transformation overtime: a situated change perspective”, Information Systems Research, Vol. 7 No. 1, pp. 63-89.

Orlikowski, W.J. and Gash, D.C. (1994), "Technological frame: making sense of information technology in organisation”, ACM Transactions on Information Systems, Vol. 12 No. 2, pp. 174-207.

Orlikowski, W.J. and Lacono, C.S. (2001), "Research commentary: desperate seeking the IT in IT research-a call to theorizing the IT artifact”, Information Systems Research, Vol. 12 No. 2, pp. 121-134.

Rogers, E. (Ed.) (1995), Diffusion of Innovation, Free Press, New York, NY.

Sarker, S., Sarker, S. and Sidorova, A. (2006), "Understanding business process change failure: an actor network perspective", Journal of Management Information Systems, Vol. 23 No. 1, pp. 51-86.

Schwarz, A. and Chin, W. (2007), "Looking forward: toward an understanding of the nature and definition of IT acceptance", Journal of the Association for Information Systems, Vol. 8 No. 4, pp. 230-243.

Sheehan, J. (2006), "Understanding service sector innovation", Communication of the ACM, Vol. 49 No. 11, pp. 43-47.

Silva, L. (2007), "Post-positivist review of technology acceptance model", Journal of the Association for Information Systems, Vol. 8 No. 4, pp. 255-266.

Simpson, M. and Docherty, A. (2004), "E-commerce adoption support and advice for UK SMEs", Journal of Business and Enterprise Development, Vol. 11 No. 3, pp. 315-328.

\section{ICT's adoption} in SMEs 
ITP

27,1

82
Swanson, E.B. and Ramiller, N.C. (2004), "Innovating mindfully with information technology", MIS Quarterly, Vol. 28 No. 4, pp. 553-583.

Tatnall, A. and Jerzy, L. (2003), "The internet e-commerce and older people: an actor-network approach to researching reasons for adoption and use", Logistic Information Management, Vol. 16 No. 1, pp. 56-63.

Teo, T.H.S., Srrivastava, S.C., Ranganathan, C. and Loo, J.W.K. (2011), “A framework for stakeholder oriented mindfulness: case of RFID implementation at YCH Group, Singapore”, European Journal of Information Systems, Vol. 20 No. 4, pp. 201-220.

Venkatesh, V., Davis, F. and Morris, M.G. (2007), "Dead or alive? The development trajectory and future adoption research", Journal of Association for Information Systems, Vol. 8 No. 4, pp. 267-286.

Walden, E.A. and Browne, G.J. (2009), "Sequential adoption theory: a theory for understanding herding behaviour in early adoption of novel technologies", Journal of the Association for Information Systems, Vol. 10 No. 1, pp. 31-62.

Walsham, G.W. (1997), "Actor network theory and IS research: current systems and future prospect", in Lee, A.S., Liebenau, J. and Degross, J.I. (Eds), Information Systems and Qualitative Research, Campman and Hall, London.

Williams, M., Dwivedi, Y.K., Lal, B. and Schwarz, A. (2009), "Contemporary trends and issues in IT adoption and diffusion research", Journal of Information Technology, Vol. 24 No. 1, pp. 1-10.

\section{Corresponding author}

Professor Yanqing Duan can be contacted at: yanqing.duan@beds.ac.uk

To purchase reprints of this article please e-mail: reprints@emeraldinsight.com Or visit our web site for further details: www.emeraldinsight.com/reprints 